\title{
Kommerzialisiertes Spielfeld
}

Von Renate Hackel-de Latour

$\mathrm{D}$ as Jahr 2016 - ein Jahr der Mega-Events im Sport: Fußball-Europameisterschaft in Frankreich, Leichtathletik-Europameisterschaft in Amsterdam und Olympische Spiele in Rio de Janeiro. Mediale Sportgroßereignisse erreichen weltweit milieu- und kulturübergreifend ein viele Millionen großes Publikum. Im Fernsehen besitzt der Sport einen hohen Stellenwert, denn die Übertragung von Sportereignissen gehört zu den reichweitenstärksten Angeboten des Mediums. Neben der soziokulturellen Dimension hat sich um den Sport eine profitable, globale Industrie entwickelt: der Wettbewerb um Übertragungsrechte, die Auslandsvermarktung, das Merchandising. Nicht nur die Kommerzialisierung sondern auch Korruption, organisierte Kriminalität und Doping gehören zu den Schattenseiten des Profisports. Kritische Sportjournalisten dokumentieren eine explodierende Anzahl an Fällen. Nachzulesen ist das zum Beispiel auf dem seit 2012 existierenden Blog fussballdoping.de, der mittlerweile bei CORRECT!V, dem ersten gemeinnützigen Recherchezentrum im deutschsprachigen Raum, eingebunden ist. Und natürlich sind die Schattenseiten des Sports ein relevantes Thema im noch relativ jungen Forschungs- und Berufsfeld Sport und Medien.

Die im September 2014 gegründete Ad-hoc-Gruppe „Mediensport \& Sportkommunikation“ in der Deutschen Gesellschaft für Publizistik und Kommunikationswissenschaft will Forschungsaktivitäten bündeln und einen Beitrag zur interdisziplinären Vernetzung mit sportwissenschaftlichen Teildisziplinen leisten. Veröffentlichungsmöglichkeiten gibt es in der 2015 online gegangenen Publikation „Journal für Sportkommunikation und Mediensport" (www.medien-sport-journal.de). Die beiden Sprecher der Gruppe kommen in dem Schwerpunkt „Sport und Medien“ dieses Heftes zu Wort.

Holger Ihle macht den Auftakt mit einer Bestandsaufnahme und Systematisierung des Forschungsfeldes. Er verdeutlicht in seinem Beitrag die Unterschiede der internationalen und
Dr. Renate

Hackel-de Latour ist Akademische

Direktorin am

Studiengang

Journalistik der

Katholischen

Universität EichstättIngolstadt und

Redakteurin von Communicatio Socialis. 
deutschen Forschungstraditionen und zeigt mögliche Entwicklungslinien für die Sportkommunikationsforschung auf. Die vielfältigen sozialen, ökonomischen und publizistischen $\mathrm{Zu}$ sammenhänge von Sport und Medien erfordern interdisziplinäre Perspektiven. Im Mainstream der Sport-Medien-Forschung steht der Leistungssport, und dort der Premiumsport mit dem Fußball auf Platz 1. Mittlerweile ist die Sport-Medien-Forschung jedoch breiter geworden und berücksichtigt auch andere Facetten wie etwa den Behindertensport oder das Thema Migration und Sport sowie die Repräsentation von Frauen im Sport.

Mit ausgewählten, zum Teil spektakulären kommunikationsethischen Problembereichen der Sportberichterstattung, die in Kontext zum Berufsverständnis der Sportjournalisten gebracht werden, befasst sich Jörg-Uwe Nieland. Dabei differenziert er zwischen "sports journalism“ und „sports broadcasting“. Mit dieser Unterscheidung erfolgt eine Unterteilung in den kritischen Sportjournalismus auf der einen Seite und die unterhaltend-informative Berichterstattung über ein Sportereignis auf der anderen Seite. Die Leistungen und die Verantwortung des Sportjournalismus sind laut dem Autor dann als problematisch einzuschätzen, wenn es beispielsweise zum kumpelhaften Miteinander mit den Sportstars kommt. Schließlich diskutiert Nieland, ob die Leitlinien des Verbandes der Sportjournalisten eine Grundlage für die kritische Begleitung des Sports bilden und damit die problematischen Muster der Berichterstattung durchbrechen könnten. „Sports journalism“ benötige nämlich, so sein Fazit, eine Mediensportethik als Pflichten-, Tugend-, Prinzipien-, und Strebensethik.

Fußballstars, die exklusiv vereinseigenen Medien Interviews geben, und traditionelle Medien, deren Informationszugang mehr und mehr eingeschränkt wird: Über die Selbstberichterstattung des Sports und damit eine Verwischung der Grenzen von PR und Journalismus am Beispiel von Club-TV schreiben Thomas Horky und Thomas Hestermann. Dazu präsentieren sie u. a. die Befunde einer Leitfaden-Befragung von 22 Vertretern des Corporate Publishing insbesondere zu Themen des vereinseigenen Sportfernsehens.

Den Abschluss des Schwerpunktes macht Regina Greck mit ihrer Analyse der Berichterstattung über die Olympischen Winterspiele 2014 in Sotschi. Sie untersucht überregionale Printmedien hinsichtlich ihrer politischen Themenschwerpunkte und fragt die Rezipient_innen, welche Aspekte sie wahrgenommen haben. 


\section{Unsere Titelbilder}

Wortwörtlich „auf Kuschelkurs“ gingen Sport und Medien kurz nach dem Finale der Fußballweltmeisterschaft 2010 in Südafrika. Voller Freude über den WM-Triumph seiner Mannschaft traf Spaniens Torhüter und Kapitän Iker Casillas nach dem Schlusspfiff zum Interview auf Sara Carbonero, Sportjournalistin beim spanischen TV-Sender "Telecinco" - und zugleich seine Lebensgefährtin. Die Fernsehreporterin will über das zurückliegende Spiel sprechen, fragt ihn zu seinen Gefühlen nach dem Titelgewinn, als Casillas sie mit einem Kuss unterbricht und wortlos in die Kabine verschwindet. „Madre mía“ (meine Güte) entfährt es Carbonero, dann gibt sie zurück ins Studio. Be-

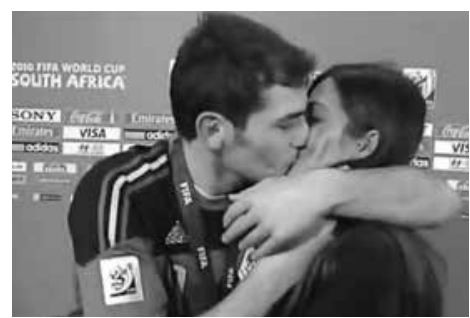
reits während der WM war über das Paar diskutiert worden. Der Madrider Presseverband bezeichnete den Einsatz von Carbonero sogar als „Schande“, weil der Journalistin die kritische Distanz fehle. Millionen Zuschauer dagegen waren entzückt. (Screenshots: Youtube) 